\title{
HIBRIDACÕ̃ES DA CULTURA ACADÊMICA COM A CIBERCULTURA: ANÁLISE DAS PRÁTICAS ACADÊMICAS NO AMBIENTE VIRTUAL DE APRENDIZAGEM MOODLE
}

\author{
Lebiam Tamar Gomes Silva ${ }^{1 *}$ \\ ORCID: https://orcid.org/0000-0001-8977-3795 \\ Irinalda da Silva Bezerra ${ }^{2 * *}$ \\ ORCID: https://orcid.org/0000-0003-0025-4038
}

RESUMO: O texto apresenta os resultados de uma pesquisa de iniciação científica (PIBIC) sobre a cultura acadêmica e o processo de hibridação com a cibercultura. O estudo teve o objetivo geral de verificar de que maneira as mediações entre os aprendentes e as tecnologias intelectuais digitais favorecem ou restringem a ressignificação da cultura acadêmica. Para atendê-lo, a pesquisa buscou identificar diferentes práticas acadêmicas de uso do ambiente virtual de aprendizagem (AVA) Moodle e analisar seus elementos constituintes. Trata-se de uma pesquisa etnográfica, fundamentada na perspectiva intercultural, segundo Canclini e MartínBarbero, vinculada aos Estudos Culturais da Educação. Os resultados apontaram que o AVA Moodle não tem favorecido a hibridação da cultura acadêmica com a cibercultura, em razão, principalmente, da episteme que governa o ensino e a aprendizagem na universidade. Constatou-se que as práticas e os elementos da cultura acadêmica que foram analisados tendem a reproduzir o paradigma de ensino vigente na instituição investigada.

Palavras-chave: Cultura acadêmica; Ensino superior; Estudos culturais da educação; Tecnologias digitais.

HYBRIDIZATION OF ACADEMIC CULTURE WITH CYBERCULTURE: ANALYSIS OF ACADEMIC PRACTICES IN MOODLE, A VIRTUAL LEARNING ENVIRONMENT

ABSTRACT: The paper presents the results of a scientific initiation research (PIBIC) about academic culture and its process of hybridization with cyberculture. The study had the general purpose of verifying in what manners the mediations between learners and digital intellectual

1 Universidade Federal da Paraíba, João Pessoa, PB, Brasil.

${ }^{2}$ Instituto de Educação Superior da Paraíba, Cabedelo, PB, Brasil.

"Doutora em Educação pela Universidade Federal da Paraíba (UFPB). Professora Adjunta do Departamento de Habilitações Pedagógicas, do Centro de Educação. Vice-coordenadora do Grupo de Pesquisa GEINCOS. E-mail:<lebiamsilva@ce.ufpb.br > .

"Pedagoga pela Universidade Federal da Paraíba (UFPB). Designer Educacional do Instituto de Educação Superior da Paraíba (IESP). E-mail: < irinaldabezerra@gmail.com>. 
technologies favor or restrict the resignification of academic culture. In order to do so, the research sought to identify different academic practices of usage of the virtual learning environment (VLE) Moodle and to analyze the elements that constitute it. It is an ethnographic research, substantiated on intercultural perspective, according to Canclini e Martín-Barbero, linked to the Cultural Studies of Education. The results pointed that the VLE Moodle platform has not favored the hybridization of academic culture with cyberculture, mainly because of the episteme that rules teaching and learning in universities. It was found that the practices and elements analyzed on academic culture tend to reproduce the current teaching paradigm at the investigated institution.

Keywords: Academic culture; Higher education; Cultural studies of education; Digital technologies.

\section{INTRODUĈ̣̃O}

Entre os vários desafios educacionais da atualidade, as instituições de ensino superior têm se defrontado com o de incorporar as tecnologias intelectuais digitais na cultura acadêmica, na perspectiva de disponibilizar essas tecnologias e realizar práticas acadêmicas que não só favoreçam a um uso instrumental por docentes e discentes em suas atividades de estudo ou de trabalho como também deem condições para a crítica das práticas midiáticas contemporâneas e para uma participação mais criativa e transformadora nas realidades educacional e social.

Este texto foi escrito a partir dos resultados do plano de ação 1 de uma pesquisa de iniciação científica desenvolvida com o objetivo de investigar de que maneira as mediações entre os aprendentes (docentes e discentes) $e$ as tecnologias intelectuais digitais favorecem ou restringem a ressignificação da cultura acadêmica. A pesquisa PIBIC foi um desdobramento do estudo sobre o tema, analisando blogs educativos, realizado na tese de Doutorado, defendida por Bezerra, L. (2011). Os dados do relatório final PIBIC tiveram ainda a sua análise ampliada e aprofundada no trabalho de conclusão de curso de graduação da discente bolsista (BEZERRA, I., 2016).

Os dados apresentados visaram atender aos seguintes objetivos específicos:

$\checkmark$ Identificar diferentes práticas acadêmicas de uso das tecnologias intelectuais digitais no ambiente virtual de aprendizagem - Moodle;

$\checkmark$ Analisar os elementos constituintes das práticas acadêmicas mediadas por tecnologias intelectuais digitais no ambiente 
virtual de aprendizagem - Moodle.

A discussão proposta neste estudo partiu da hipótese de que é possível fazer uma análise da cultura acadêmica que não se fundamente em uma concepção pragmática e determinista da mediação do ensino e da aprendizagem por meio de tecnologias intelectuais digitais. A linha de raciocínio adotada foi a que visa a pensar na ressignificação da cultura acadêmica a partir de um processo de hibridação com a cibercultura que, talvez, esteja ocorrendo por complexificação, e não, por simples substituição da cultura acadêmica vigente. $\mathrm{O}$ desafio da análise de dados realizada consistiu em tentar compreender esse processo de hibridação com base nas permanências e nas rupturas observadas nas práticas acadêmicas investigadas.

\section{REFERENCIAL TEÓRICO}

Nesta pesquisa, consideramos a possibilidade de misturar os elementos constituintes de duas culturas distintas - a cultura acadêmica e a cibercultura. Para isso, apoiamo-nos em uma base teórica na perspectiva intercultural proposta por Canclini (2008) e na teorização da cultura escolar formulada por Pérez-Gómez (2001). Para este último autor, as instituições educativas não são totalmente determinadas pelas exigências e pelas demandas sociais nem completamente autônomas em seus processos de ressignificação da cultura escolar. Isso ocorre porque nelas há

[...] o cruzamento de culturas que provoca tensões, aberturas, restrições e contrastes na construção de significados [...] que ressaltam o caráter sistêmico e vivo dos elementos que influem na determinação dos significados e nas condutas dentro da instituição escolar (PÉREZ-GÓMEZ, 2001, p. 12).

Assim, esse autor considera que as instituições educativas têm identidade e relativa autonomia por meio da mediação reflexiva que realizam dos influxos plurais exercidos por essas diferentes culturas sobre as novas gerações. Isso as distingue das outras instituições e instâncias de socialização, porque sua função educativa consiste em oferecer aos aprendentes a possibilidade de compreenderem o valor e os significados dos influxos que recebem durante a participação na vida cultural de sua comunidade (PÉREZ GÓMEZ, 2001).

A análise da cultura acadêmica, através de sua hibridação com a cibercultura, visou ressaltar os aspectos políticos e pedagógicos em questão na interculturalidade e sua relevância sobre os aspectos pragmáticos e instrumentais que, de modo geral, têm predominado 
nas concepções e nas práticas culturais de apropriação e de uso das tecnologias nas instituições educativas. Os conceitos centrais deste estudo foram: tecnologias intelectuais digitais, cultura acadêmica, cibercultura, hibridação, aprendência e aprendentes. Para compreender bem mais as análises realizadas neste estudo, apresentamos abaixo suas definições e seus autores.

O termo tecnologias intelectuais digitais (TID) foi cunhado a partir da compreensão formulada por Lévy (1993) de que elas auxiliam o sistema cognitivo humano e, portanto, integram uma rede complexa composta de nós biológicos, interfaceados por nós técnicos, semióticos, institucionais e culturais. Em outras palavras, entendemos que os aprendentes (docentes e discentes) e as TID compõem a rede complexa da vida em que a cognição se realiza.

Os ambientes virtuais de aprendizagem (AVA) foram as TID sobre as quais a investigação se debruçou.

[...] [Os AVA] são espaços de aprendizagem na web em que os interlocutores do processo [educativo] interagem entre si, cooperando e desenvolvendo ideias, ultrapassando fronteiras geográficas, culturais, de idade e de tempo, para construir aprendizagens significativas (SOARES; VALENTINI; RECH, 2011, p. 43).

Para que essas ações sejam concretizadas, uma série de elementos dispostos nesses softwares pode ser utilizada por docentes e discentes para mediar a aprendizagem. Como a maioria dos AVA é paga, e seus elevados custos tornam o acesso a muitos deles limitado, com o passar do tempo, foram sendo desenvolvidas plataformas gratuitas. Em nível mundial, o Moodle (Object-Oriented Dynamic Learning Environment) é um exemplo de plataforma gratuita que, cada vez mais, vem sendo utilizada, principalmente, no Ensino Superior (PAIVA, 2010).

A cultura acadêmica é definida por Pérez Gómez (2001, p. 259) como "o conjunto de significados cuja aprendizagem se pretende provocar nas novas gerações através da instituição escolar". Duarte (2008, p. 653) emprega o termo cultura acadêmica ou universitária para se referir, especificamente, às "práticas educativas realizadas por docentes e discentes na universidade". Esse conceito tem ênfase na imaterialidade da cultura acadêmica e coaduna-se com as concepções idealistas e cognitivistas da cultura. ${ }^{1}$

Fundamentando-nos na definição lato sensu de cultura de Bizzocchi (2003), formulamos, por analogia, um conceito de cultura acadêmica para esta pesquisa como um conjunto complexo dos processos de produção, circulação e consumo de significados, realizados através das práticas acadêmicas e compartilhados por meio dos discursos pedagógicos nas instituições educativas. Para Lévy 
(1999, p. 17), a cibercultura é concebida como um "[...] conjunto de técnicas (materiais e intelectuais), de práticas, de atitudes, de modos de pensamento e de valores que se desenvolvem juntamente com o crescimento do ciberespaço".

Contrapondo-se à ideia clássica de pureza da/s cultura/s, Canclini (2008) propõe que se analise a categoria cultura com base em sua heterogeneidade e nas misturas, e, não, na ideia de homogeneidade e de pureza. Assim, o autor emprega o termo hibridação para definir os "processos socioculturais nos quais estruturas ou práticas discretas, que existiam de forma separada, se combinam para gerar novas estruturas, objetos e práticas" (CANCLINI, 2008, p. XIX). Para ele, a hibridação pressupõe a noção de interculturalidade, em lugar da ideia de multiculturalidade. Esse autor explica que

[...] ambos os termos implicam dois modos de produção do social: a multiculturalidade supõe a aceitação do heterogêneo; [enquanto] a interculturalidade implica que os diferentes são o que são, em relações de negociação, conflito e empréstimos recíprocos (CANCLINI, 2007, p. 17).

Assim, as noções de hibridação e de interculturalidade foram os elementos teóricos para articular uma perspectiva de análise por meio da qual seja possível investigar a cultura acadêmica com base no que emerge de suas misturas com a cibercultura.

Nesta pesquisa, o termo aprendência foi usado para se referir ao processo de composição de redes virtuais de conhecimento surgidas com as mediações estabelecidas entre os aprendentes (docentes e discentes) e as tecnologias intelectuais digitais. Essa definição fundamenta-se na proposição de Assmann (1998), segundo a qual aprender não significa acumular informações, mas compor uma rede complexa e dinâmica de interações neuronais, que se organiza continuamente no cérebro humano. Com essa perspectiva, tanto os docentes quanto os discentes são definidos como aprendentes, porque são agentes cognitivos que se encontram em processo ativo de aprendência.

\section{METODOLOGIA}

A pesquisa consistiu de um estudo de caráter exploratório, desenvolvido por uma estudante de graduação do programa institucional de iniciação científica da Universidade Federal da Paraíba (UFPB). Foi realizada em dois anos, no período de 2013/2014 e 2014/2015 e seguiu as seguintes etapas: revisão de literatura em bases de dados digitais (CAPES e IBICT); leituras e discussões acerca 
dos conceitos centrais e dos aportes teóricos; entrada no campo da pesquisa; elaboração dos instrumentos; coleta dos dados; categorização e análise dos dados; e organização e escrita dos relatórios parciais e finais. A equipe de pesquisadores foi composta pela professora orientadora e por uma estudante do Curso de Pedagogia (bolsista).

A categoria cultura acadêmica requereu a escolha por uma metodologia de pesquisa qualitativa, por meio da qual fosse possível identificar e compreender seus elementos essenciais. Assim, a etnografia virtual foi o enfoque metodológico escolhido para se abordar o problema formulado. Contribuíram teoricamente para o desenho desta pesquisa autores como Rocha e Montardo (2005), Silverman (2009) e Sandín Esteban (2010).

A etnografia virtual é um método usado, principalmente, para investigar comunidades online, com o objetivo de identificar os hábitos de consumo. Para tanto, utilizam-se procedimentos e instrumentos de pesquisa relacionados às interfaces de comunicação disponíveis na rede virtual, como correio eletrônico (e-mails), vídeo ou audioconferências, listas e fóruns de discussão, entre outros (KOZINETS, 2002 apud ROCHA; MONTARDO, 2005). Embora a etnografia seja um método de pesquisa originário da Antropologia, é usado recorrentemente nas Ciências Sociais e na Educação. Esses estudos, tradicionalmente, procuram apreender os significados sociais e as atividades comuns das pessoas. Para isso, são feitos por meio da coleta sistemática de dados e envolvem a participação direta do pesquisador no campo investigado (SILVERMAN, 2009).

O ciberespaço foi o contexto cultural em que as práticas acadêmicas foram investigadas. Na Universidade Federal da Paraíba (UFPB), as salas de aula virtuais se materializam por meio do ambiente virtual de aprendizagem (AVA) - Moodle, que se constituiu como campo de pesquisa.

A amostra do estudo foi composta de 71 salas de aula virtuais do semestre letivo de 2013.1, disponíveis no Moodle dos cursos presenciais de graduação da Universidade Federal da Paraíba, Campus I, João Pessoa - PB. Colaboraram com a pesquisa, nas duas etapas (2013/2014/2015), 14 docentes responsáveis pelo processo de aprendência realizado nas salas de aula virtuais selecionadas.

Os instrumentos usados para a coleta dos dados foram: formulário estruturado, questionário estruturado online e entrevista semiestruturada. ${ }^{2} \mathrm{O}$ corpus de dados foi composto da seguinte documentação: formulários estruturados para a análise dos registros documentais das salas de aula virtuais (Moodle), questionários 
estruturados online e documentos de transcrição das entrevistas.

$\mathrm{Na}$ primeira etapa da pesquisa, foram identificadas 283 salas de aula virtuais no Moodle presencial. Dentre elas, foram selecionadas 71 para compor a amostra investigada. Os docentes das salas de aula virtuais selecionadas foram convidados a participar da pesquisa e informados sobre os procedimentos técnicos de análise de interface, e a categorização das salas de aula virtuais foi executada.

Para complementar esse conjunto de dados coletados, foi aplicado um questionário estruturado online aos 30 docentes que concordaram em colaborar com o estudo. Foram obtidas dez respostas de docentes dos Cursos de Administração, Farmácia, Fisioterapia, Matemática, Ciências Contábeis, Pedagogia e Odontologia. Esse instrumento foi dividido em três categorias: planejamento, execução e avaliação, que investigavam aspectos relativos a trabalho docente, currículo, metodologias de ensino, relação docente-discentes e avaliação das atividades propostas.

A segunda etapa da coleta dos dados (2014/2015) começou com a consulta à amostra das 71 salas analisadas na pesquisa (2013/2014); em seguida, foram examinados os dez questionários respondidos e enviados. Com base nessa análise prévia, foram selecionadas 14 salas de aula virtuais, que apresentavam características favoráveis à hibridação da cultura acadêmica com a cibercultura. Nessa fase do estudo, aplicou-se a entrevista semiestruturada, cujo roteiro foi composto de questões relacionadas às categorias teóricas e empíricas definidas na fase anterior do estudo. Nessa segunda etapa, seis docentes foram entrevistados (Cursos de Pedagogia, Odontologia, Rádio/TV e Ciência da Computação).

Os dados foram analisados seguindo-se os procedimentos de análise de registros etnográficos apresentados por Silverman (2009), segundo o qual a própria organização da entrevista semiestruturada configura-se como categorização inicial para os dados que, em um primeiro momento, foi orientada pelos referenciais teóricos em articulação com o problema da pesquisa. Várias leituras dos dados foram realizadas, e os recortes significativos das falas correspondentes a cada categoria teórica foram retirados e organizados em um quadro. A cada nova leitura, os dados eram refinados, e as recorrências eram organizadas em uma coluna específica. Finalizada a categorização dos dados, procedemos à leitura e à discussão, triangulando os dados coletados na fase anterior, as categorias teóricas e as categorias empíricas do estudo para formular as conclusões possíveis para o 
problema proposto pela pesquisa.

\section{RESULTADOS E DISCUSSÕES}

Na busca por respostas para a questão norteadora da pesquisa, apresentamos, a seguir, parte da discussão dos resultados feita com base na análise dos dados coletados. O texto discute sobre cinco elementos constitutivos da cultura acadêmica investigada: as salas de aula virtuais, o trabalho docente, o currículo, as práticas acadêmicas no AVA e a avaliação.

\section{SALAS DE AULA VIRTUAIS}

O ciberespaço é o lócus das práticas que constituem a cibercultura. Por isso, decidiu-se lançar um olhar investigativo sobre a forma como as práticas acadêmicas se configuram em ambientes virtuais de aprendizagem (AVA). O Moodle ${ }^{3}$ (Object-Oriented Dynamic Learning Environment) é o AVA utilizado pela UFPB e analisado nesta pesquisa. Ele foi desenvolvido como software livre por Martin Dougiama e conta com colaboradores do mundo inteiro, que trabalham para aprimorá-lo.

Os conteúdos disponíveis nas 71 salas de aula virtuais do AVA Moodle dos cursos presenciais (UFPB, Campus I) foram analisados a partir dos itens elencados em uma ficha de análise de interface. Como categorias teóricas, definimos três possibilidades de classificar as salas de aula virtuais, tomando como analogia a tipologia proposta por Gomes (2005 apud BEZERRA, 2011), ao estudar os blogs educativos:

a) Espaço de disponibilização de informação: sala de aula virtual que é utilizada pelo docente para publicar conteúdos diversos e disponibilizar informações relacionadas aos estudos em sua disciplina. Nessas salas virtuais, em geral, os discentes não participam como coautores de conteúdos;

b) Espaço de intercâmbio e de colaboração: sala de aula virtual usada, principalmente, para intercâmbios entre os docentes e os discentes, como a troca permanente de mensagens e a publicação de informações ou produção compartilhada de conteúdos/conhecimentos;

c) Salas virtuais com ambas as finalidades didáticas: são salas virtuais que atendem às duas finalidades didáticas anteriores.

Os dados coletados neste estudo indicaram que quarenta 
salas de aula virtuais dos cursos presenciais da UFPB podem ser classificadas como espaços de disponibilização de informações pelos docentes. Nessas salas, predomina uma participação passiva dos discentes no processo de aprendência. Em geral, as práticas predominantes ainda são compostas de elementos de uma cultura acadêmica centrada no ensino, na ação do docente, na disponibilização e no acesso à informação especializada, no estudo individual e na avaliação classificatória e burocrática.

Assim, foi possível constatar que predomina uma concepção da tecnologia como um ente autônomo, segundo a qual se presume que ela, por si só, tem a capacidade de transformar o processo de ensino e aprendizagem. Esse entendimento equivocado contribui para que o AVA Moodle seja subutilizado, já que essa tecnologia é inserida na cultura acadêmica de modo acrítico e inadequado, priorizando-se o desenvolvimento de práticas instrumentais que não exploram o potencial pedagógico dessa tecnologia intelectual digital (BEZERRA, 2011).

É importante ressaltar que a disposição das informações, dos recursos didáticos e das atividades no AVA pode ou não favorecer o acesso, o estudo e a comunicação entre os aprendentes docentes e discentes. Nesse contexto, a configuração da interface da sala de aula virtual é um aspecto fundamental para a gestão do processo de aprendência, porque pode favorecer ou restringir a interação, o diálogo e a colaboração entre os aprendentes.

No AVA Moodle, por exemplo, há sete tipos de recursos didáticos e onze de atividades disponíveis. Entretanto, vimos que os docentes não utilizam a maior parte deles. O link para um arquivo ou site foi o recurso didático mais empregado. As salas de aula virtuais analisadas continham 1363 links, por meio dos quais os docentes disponibilizavam arquivos em diferentes formatos (texto, imagem, vídeo, áudio) ou endereços de páginas da Web (URLs) para os discentes fazerem download e estudarem. Grande parte desses conteúdos não é de autoria dos docentes.

As atividades propostas mais recorrentes foram lição (278), fórum (202) e questionário (106). As atividades do tipo fórum e glossário podem proporcionar rupturas com as práticas acadêmicas vigentes porque contribuem para que os discentes participem de forma mais ativa e interativa do processo de aprendência, enquanto as atividades dos tipos lição e questionário tendem a restringir o diálogo e a produção compartilhada do conhecimento. Em geral, nelas o docente propõe questões, e os discentes dão as respostas que, depois, são avaliadas e recebem uma nota. Essa prática estabelece uma finalidade classificatória e burocrática para a avaliação da aprendizagem. 
No tocante às atividades feitas no AVA Moodle, os docentes dispõem de outras possibilidades para propor uma participação mais ativa, interativa e colaborativa aos discentes. Além do fórum de discussão e do glossário, por exemplo, existem atividades, como chat, blog e wiki, com os quais os discentes poderiam se engajar em processos de discussão, interpretação, reelaboração do pensamento e produção colaborativa e compartilhada de conhecimentos.

Os dados coletados durante a análise de interface das salas de aula virtuais foram comparados com as informações que os docentes apresentaram nas entrevistas. Os recortes de fala apresentados abaixo destacam algumas das recorrências identificadas e possibilitam uma síntese conclusiva sobre a análise das salas de aula virtuais.

QUADRO 1. Análise de Interface

\begin{tabular}{|c|c|c|}
\hline Identificação & Categoria & \multicolumn{1}{c|}{ Recorte da fala } \\
\hline DOCENTE 2 & $\begin{array}{c}\text { Limitação } \\
\text { tecnológica }\end{array}$ & $\begin{array}{l}\text { 0 fórum é (pausa) [...] parece que já foi configurado } \\
\text { dessa forma. Perguntas e respostas, eu acho. }\end{array}$ \\
\hline DOCENTE 2 & $\begin{array}{c}\text { Silêncio } \\
\text { discente }\end{array}$ & $\begin{array}{l}\text { Quando eu saí, a interação foi mais interessante } \\
\text { (pausa) [...] Mas, assim (pausa) Aumentou a } \\
\text { interação na ausência do professor. }\end{array}$ \\
\hline DOCENTE 4 & $\begin{array}{c}\text { Silêncio } \\
\text { discente }\end{array}$ & $\begin{array}{l}\text { [...] porque às vezes quando [...] a gente diz alguma } \\
\text { coisa como verdade (absoluta), ou seja, pode botar } \\
\text { abaixo tudo aquilo que ele estava respondendo } \\
\text { àquela pergunta, entendeu? Então, a gente evita. }\end{array}$ \\
\hline DOCENTE 5 & $\begin{array}{c}\text { Precarização do } \\
\text { trabalho docente }\end{array}$ & $\begin{array}{l}\text { [...] Só que isso aí que eu tô falando era mais ou } \\
\text { menos uns dois anos atrás. A gente tinha mais } \\
\text { disponibilidade pra fazer. }\end{array}$ \\
\hline DOCENTE 6 & $\begin{array}{l}\text { Precarização do } \\
\text { trabalho docente }\end{array}$ & $\begin{array}{l}\text { Na verdade, também, a UFPB poderia dar condições } \\
\text { melhores pra gente. [...] a gente trabalha em } \\
\text { condições de estrutura física precária. }\end{array}$ \\
\hline
\end{tabular}

Fonte: Dados coletados pela pesquisa em março de 2015.

O docente não têm habilidades técnicas necessárias para a configuração do AVA, porque é possível modificar o tipo de fórum de acordo com o objetivo do ensino que foi estabelecido e a interação que se deseja promover entre os participantes.

Nas práticas acadêmicas das salas de aula virtuais, ainda é recorrente a centralização da fala pelo docente e o silêncio discente, instituídos pela histórica hierarquização de poder entre eles. Assim, 
há mais interação entre os discentes quando o docente está ausente. Isso se justifica porque eles não se sentem inibidos, controlados ou avaliados em suas interações.

Conforme relatou o docente 4, ele evita dar o feedback no AVA, por notar que, quando o faz, seus discentes o encaram como verdade absoluta e desconsideram as próprias construções intelectuais. Conforme as duas situações expostas, foi possível inferir que os discentes continuam a achar que o docente é o detentor do conhecimento. O estudo mostrou, também, que o trabalho do docente ainda é precário, devido ao excesso de atividades que lhe são atribuídas na Universidade, e isso o impossibilita de realizar práticas acadêmicas inovadoras e dialógicas nas salas de aula virtuais.

A última das recorrências apresentadas tratou da ligação entre a qualidade do ensino e da aprendizagem e a estrutura física e organizacional da universidade, o que demonstrou que a instituição deve possibilitar os meios e as condições materiais e imateriais adequados para que o docente consiga fazer seu trabalho com a qualidade acadêmica almejada.

As recorrências encontradas nas falas dos docentes confirmaram a subutilização do ambiente virtual de aprendizagem, observada durante a análise das interfaces das salas de aula virtuais, o que nos levou a afirmar que nelas predominam práticas acadêmicas instrumentais. Nesse contexto educativo, os aprendentes (docentes e discentes) não têm a oportunidade de discutir sobre os recursos didáticos e as atividades realizadas e de decidir sobre os mais adequados e deixam de criar e de experimentar práticas acadêmicas que lhes propiciariam outros modos de ensinar, de aprender e de explorar o potencial pedagógico do AVA Moodle.

\section{TRABALHO DOCENTE}

Os dados apresentados nesta seção foram coletados por meio de um questionário semiestruturado, que foi aplicado aos docentes das 14 salas de aula virtuais, selecionadas em razão de se caracterizarem, simultaneamente, como espaços de disponibilização de informação por parte do professor, de intercâmbio e de colaboração (GOMES, 2005).

As análises revelaram que, no ambiente virtual de aprendizagem, o trabalho docente é feito individualmente por $60 \%$ dos participantes deste estudo. Isso corrobora o que Pérez Gómez (2001) também constatou em sua análise da cultura escolar e que denominou de isolamento docente. $\mathrm{O}$ autor explica que esse isolamento consiste em se fazer um trabalho individualizado, por se 
entender, equivocadamente, a autonomia do professor como uma ação livre de pressões e de controles externos, exercida com base em uma autoridade arbitrária para governar a própria ação educativa. Essa concepção colabora para que o trabalho docente seja realizado de modo fragmentado e restrinja a proposição de novas ideias na universidade. Além disso, o isolamento docente favorece o estresse e inviabiliza o reconhecimento do êxito (PÉREZ GÓMEZ, 2001).

$\mathrm{O}$ autor ressalta que a autonomia docente precisa ser compreendida como uma busca singular da identidade profissional, que é construída a partir da reflexão individual, articulada com o trabalho colaborativo com os pares acadêmicos. O resultado dessa concepção é um trabalho docente que resulta em processos de pensamentos, análises e propósitos integrantes de um projeto institucional comum (PÉREZ-GÓMEZ, 2001).

QUADRO 2. Trabalho Docente

\begin{tabular}{|c|c|c|}
\hline Identificação & Categoria & Recorte da fala \\
\hline DOCENTE 6 & $\begin{array}{l}\text { Precarização do } \\
\text { trabalho docente }\end{array}$ & $\begin{array}{l}\text { [...] Por exemplo, na minha área específica, não tem } \\
\text { professores com quem eu possa dialogar tanto. }\end{array}$ \\
\hline DOCENTE 2 & $\begin{array}{l}\text { Isolamento } \\
\text { docente }\end{array}$ & $\begin{array}{l}\text { Nós, infelizmente, temos uma cultura de autonomia } \\
\text { que nos leva a um isolamento [...] não temos } \\
\text { oportunidade de discutir o nosso conteúdo. }\end{array}$ \\
\hline DOCENTE 2 & $\begin{array}{l}\text { Autonomia } \\
\text { docente }\end{array}$ & $\begin{array}{l}\text { A autonomia, na minha perspectiva, é uma autonomia } \\
\text { dialogada com } 0 \text { aluno, porque é o único interlocutor } \\
\text { que acaba aparecendo no contexto institucional. }\end{array}$ \\
\hline DOCENTE 4 & $\begin{array}{l}\text { Autonomia } \\
\text { docente }\end{array}$ & $\begin{array}{l}\text { A partir da extensão, eu tive a oportunidade de } \\
\text { trabalhar com professores da Educação Física [que } \\
\text { não é o curso de origem no qual exerce sua docência] } \\
\text { nesse semestre [...]. }\end{array}$ \\
\hline
\end{tabular}

Fonte: Dados coletados pela pesquisa em março de 2015.

$\mathrm{Na}$ instituição de ensino superior investigada nesta pesquisa, o trabalho docente ainda é marcadamente individual. Os professores participantes do estudo encontram-se divididos entre possibilidades e impossibilidades de dialogar com seus pares acadêmicos. Evidenciouse a distribuição concentrada de disciplinas por docente. Outra impossibilidade é a falta de espaço e de tempo institucionais definidos e organizados para estabelecer o diálogo acadêmico entre os pares. 
Segundo Gerhard (2002), historicamente, a universidade apresentou os princípios da solidão e da liberdade como condições para o desenvolvimento do conhecimento científico. Entretanto, em relação a isso, foi possível perceber que, na universidade, a liberdade e a solidão conferidas aos docentes contribuem mais para o isolamento docente. Sobre isso, esse mesmo autor esclarece que o princípio da solidão se põe como isolamento da individualidade do docente e não exclui a necessidade do diálogo com os outros pares acadêmicos. Como fazer para romper com o isolamento entre os docentes na universidade? Que mudanças na cultura acadêmica serão necessárias e possíveis para se construir um ambiente propício ao trabalho docente colaborativo?

Os dados demonstraram o que consideramos uma limitação institucional, porquanto é a própria dinâmica da cultura acadêmica em vigor que tem impossibilitado o diálogo entre os pares. Podemos inferir que essa impossibilidade esteja associada ao excesso de atividades atribuídas aos docentes, que provoca a saturação de tarefas e de responsabilidades profissionais, conforme afirmado por Pérez Gómez (2001). Esse estado de coisas indica que é preciso reconfigurar o tempo e o espaço institucional na universidade para transformá-los em espaços de discussões e de reflexões acadêmicas.

No campo das possibilidades, foram encontradas estratégias traçadas pelos docentes para romper com esse isolamento docente e promover o diálogo acadêmico com pares internos e externos. Um docente entrevistado apresentou o discente como "o par acadêmico mais próximo" com o qual é possível dialogar. Outra possibilidade de dialogar com pares internos aconteceu entre docentes que compartilham a docência em uma mesma disciplina (em poucos casos) e entre os que constituem equipes multidisciplinares e desenvolvem projetos de pesquisa e/ou de extensão conjuntos. Assim, a extensão emergiu como uma atividade acadêmica por meio da qual é possível promover o diálogo entre os pares e articular as demais funções da universidade (a de ensino e de pesquisa), criando um espaço-tempo institucional para o compartilhamento de conhecimentos entre os docentes, os discentes e a comunidade universitária.

A devida articulação entre as funções de ensino, pesquisa e extensão é uma forma de trazer da comunidade os saberes produzidos e veiculados nela e por ela para fundamentar os estudos e as reflexões na Academia e, em seguida, devolvê-los à comunidade, devidamente sistematizados, para que contribuam para resolver os problemas reais, e a universidade, de fato, cumpra seu papel social (SANTOS, s/d).

Quanto à interlocução com pares externos, verificou-se a 
possibilidade de diálogo com docentes de outras instituições com que se tem contato, normalmente, através de grupos de pesquisa, de eventos e de publicações. Os dados confirmam que os docentes estão buscando formas de superar o isolamento instituído na cultura acadêmica por meio do exercício da autonomia que lhes é conferida. Eles empreendem ações contingenciais e criam espaços e tempos não institucionalizados, na tentativa de responder aos desafios postos pelas transformações culturais de seu tempo. Assim, podemos supor que a autonomia docente exercida na cultura acadêmica investigada não provém de uma concepção equivocada, como sugeriu PérezGómez (2001) em seu estudo, mas seja indício do protagonismo docente para o enfrentamento de questões urgentes e emergentes para as quais as regras institucionais não conseguiram ainda formular orientações/recomendações em tempo hábil.

Isso pode indicar que o dinamismo da realidade social ultrapassa temporalmente a capacidade de organizar e de gerir a universidade e impele os docentes a encontrarem soluções e a executarem ações pontuais e desarticuladas do aparato normativo e das prescrições previstas pela instituição. Assim, as rupturas oriundas dessas iniciativas docentes podem não ser resultado de uma compreensão equivocada da autonomia docente, mas da construção autônoma de práticas acadêmicas mais apropriadas à sua realidade.

\section{CURRÍCULO}

O currículo é o regente da prática docente, a partir do qual são pensados os caminhos para as aprendizagens. Para isso, precisamos repensá-lo considerando a mentalidade e o futuro dos discentes, para que seus objetivos caminhem na mesma direção que os objetivos de ensino traçados. Com as mudanças ocorridas ao longo da história da universidade, saímos de um grupo discente restrito e homogêneo, para um mais amplo, heterogêneo, que não faz parte do mesmo contexto cultural. Tais fatores são fundamentais para que possamos refletir sobre o que irá compor esse currículo, considerando o significado que terá para os discentes (CERTEAU, 2012).

As práticas acadêmicas analisadas neste estudo nos levaram a perceber um paradoxo referente ao currículo, que ilustra bem a forma como o processo de hibridação cultural se constrói: (a) As regulamentações curriculares do sistema nacional de ensino brasileiro e da universidade definem e limitam as possibilidades de ressignificar o currículo; (b) A autonomia docente e a impossibilidade do controle 
institucional rigoroso sobre o trabalho em sala de aula permitem que os docentes tomem decisões sobre a seleção e a organização dos conteúdos curriculares.

QUADRO 3. Currículo

\begin{tabular}{|c|c|c|}
\hline Identificação & Categoria & \multicolumn{1}{c|}{ Recorte da fala } \\
\hline DOCENTE 3 & $\begin{array}{c}\text { Autonomia } \\
\text { docente }\end{array}$ & $\begin{array}{l}\text { [..] a gente pode pegar disciplinas como } \\
\text { seminários, projetos integradores e as próprias } \\
\text { atividades complementares pra a gente trazer esse } \\
\text { conhecimento que está surgindo a cada dia [...]. }\end{array}$ \\
\hline DOCENTE 5 & $\begin{array}{c}\text { Precarização do } \\
\text { trabalho docente }\end{array}$ & $\begin{array}{l}\text { [...] um currículo novo não funciona sem ter uma } \\
\text { infraestrutura adequada. }\end{array}$ \\
\hline DOCENTE 5 & $\begin{array}{c}\text { Limitação } \\
\text { institucional }\end{array}$ & $\begin{array}{l}\text { [...] Se o próprio estatuto engessa os currículos, } \\
\text { a gente como curso não tem essa autonomia para } \\
\text { fazer alteração nenhuma. }\end{array}$ \\
\hline
\end{tabular}

Fonte: Dados coletados pela pesquisa em março de 2015.

Verificamos que, ainda de maneira insipiente, os docentes entrevistados buscam estratégias para apresentar conteúdos curriculares e discussões mais atualizados aos discentes. E como não é possível atualizar o currículo em curto intervalo de tempo, o docente entrevistado entendeu que se pode ressignificar o currículo das disciplinas citadas abaixo inserindo conteúdos curriculares emergentes para atender às novas demandas de formação e acompanhar a velocidade da produção e da disseminação do conhecimento científico.

O grande volume de informações e a facilidade de acesso, de circulação, de consumo, modificação e de sua obsolescência demandam ações favoráveis à flexibilização do currículo para que o ensino universitário se realize partindo de discussões que se aproximam da realidade pessoal e profissional dos discentes (PÉREZ-GÓMEZ, 2010). Isso requer uma revisão periódica do currículo.

Outro ponto evidenciado nas entrevistas foi a necessidade de considerar a subjetividade que perpassa o currículo, configurando o chamado "currículo oculto", que trata do currículo em seu sentido mais amplo, considerando as relações interpessoais e os demais aspectos que estão para além do que consta no currículo documental. Devido à forte ligação que enxergamos entre os aspectos subjetivos 
do processo de aprendência que dão corpo a esse currículo e às metodologias de ensino adotadas pelos docentes, discutiremos sobre esse ponto na seção subsequente.

Em seu relato, o docente 5 nos leva a refletir, mais uma vez, sobre as condições de trabalho, especificamente relativas à precarização na universidade. Conforme aponta, há limitações materiais que dificultam ou impedem a implementação de mudanças que refletiriam na reformulação curricular. Em sua opinião, o próprio sistema universitário não dá margem às transformações que são necessárias para reformular o currículo.

Nesse momento, dois pontos de discussão se encontram e a partir deles levantaremos algumas hipóteses: a autonomia docente e a burocracia acadêmica. A primeira, utilizada em favor da mudança curricular, e a segunda, posta como resistência a tais mudanças. Esse aparente conflito entre um elemento que favorece e outro que restringe a hibridação cultural faz parte da natureza do processo de misturas entre elementos da cultura acadêmica e da cibercultura e só nos reafirma que há tentativas de mudança que partem da consciência de sua importância para que a universidade não se distancie do seu papel social.

Isso reflete o caráter processual e incompleto das hibridações culturais. Em outras palavras, segundo o pensamento de Canclini (2008), podemos inferir que a cultura acadêmica, ao entrar em contato com a cibercultura, não permanece "pura". Porém, as mudanças provocadas a partir desse contato entre culturas distintas (hibridação) não se darão de forma radical nem completa, porque há uma parte inegociável em cada cultura que compõe o que seria sua essência, da qual ela não abrirá mão (CANCLINI, 2008). Ou seja, uma não se transformará na outra ou, ainda, a hibridação não fará surgir uma cultura acadêmica completamente diferente da institucional vigente.

\section{PRÁTICAS ACADÊMICAS NO AVA MOODLE}

O AVA - Moodle abriga uma série de possibilidades em termos de estudo e de construção de conhecimentos, potencialização da aprendizagem, participação discente, interação, exercício do protagonismo estudantil e da autonomia intelectual. Entretanto, o estudo mostrou que a maioria dos docentes que participaram da pesquisa só utilizou o ambiente virtual de aprendizagem para disponibilizar informações para os discentes. Então, o potencial pedagógico dessa tecnologia não foi devidamente explorado nas práticas acadêmicas analisadas. 
QUADRO 4. Práticas Acadêmicas no Ava

\begin{tabular}{|c|c|c|}
\hline Identificação & Categoria & Recorte da fala \\
\hline DOCENTE 2 & $\begin{array}{c}\text { Dimensão } \\
\text { humano-afetiva }\end{array}$ & $\begin{array}{l}\text { Ora, pra que que ele [o professor] vai ter um } \\
\text { conhecimento fantástico [...] se ele é ministrado } \\
\text { por meio de um processo opressor? }\end{array}$ \\
\hline DOCENTE 1 & $\begin{array}{l}\text { Natureza da área } \\
\text { de conhecimento }\end{array}$ & $\begin{array}{l}\text { A área que eu ministro aula é a área de exatas. } \\
\text { Então, exatas é curto e grosso. }\end{array}$ \\
\hline DOCENTE 6 & Planejamento & $\begin{array}{l}\text { Tentava fazer, um pouco antes da disciplina } \\
\text { começar, tanto do método da disciplina específica, } \\
\text { disponibilidade de texto e essa possibilidade de } \\
\text { diálogo nos fóruns né? [...] tentar construir junto } \\
\text { com a turma. }\end{array}$ \\
\hline DOCENTE 4 & $\begin{array}{l}\text { Descentralização } \\
\text { do conhecimento }\end{array}$ & $\begin{array}{l}\text { [...] eu tô voltando pra lá pra apresentar um } \\
\text { trabalho que foi desenvolvido por uma aluna [...], } \\
\text { que está disponível na plataforma Moodle. }\end{array}$ \\
\hline DOCENTE 5 & $\begin{array}{l}\text { Silêncio } \\
\text { discente }\end{array}$ & $\begin{array}{l}\text { [...] aí eu lembro que uma vez o aluno disse } \\
\text { "professor isso deveria ser livre!" (pausa) E eu } \\
\text { lembro que em um semestre a gente fez isso e } 0 \\
\text { índice de participação foi muito baixo, então, assim, } \\
\text { falta uma motivação para que } 0 \text { aluno participe. }\end{array}$ \\
\hline DOCENTE 2 & $\begin{array}{l}\text { Limitação } \\
\text { tecnológica }\end{array}$ & $\begin{array}{l}\text { Então, eu tenho uma coisa que eu acho que é } \\
\text { limitação minha, limitação tecnológica. }\end{array}$ \\
\hline DOCENTE 5 & $\begin{array}{l}\text { Limitação } \\
\text { tecnológica }\end{array}$ & $\begin{array}{l}\text { E a gente não tá tão habituado também com a } \\
\text { parte técnica do Moodle [...]. }\end{array}$ \\
\hline DOCENTE 6 & $\begin{array}{l}\text { Limitação } \\
\text { tecnológica }\end{array}$ & $\begin{array}{l}\text { Não sei, talvez eu tenha que aprender um pouquinho } \\
\text { melhor como me apoderar mais dessa ferramenta } \\
\text { pra chamar mais atenção dos meus alunos, pra } \\
\text { digamos, encantá-los melhor }\end{array}$ \\
\hline
\end{tabular}

Fonte: Dados coletados pela pesquisa em março de 2015.

Com essa provocação o docente 2 visou nos alertar para a necessidade de se pensar na dimensão humano-afetiva do processo de aprendência e de refletir sobre as relações em que o conhecimento é construído. A partir dessa reflexão, o docente poderá observar se há dissonância entre as concepções e os princípios educativos que defende e suas práticas acadêmicas. É a partir desse mesmo ponto de reflexão que ele poderá distinguir autoridade de autoritarismo 
e optar por planejar aulas em que os/as discentes são sujeitos ativos e participam do processo de construção do conhecimento. Assim, trata-se de um processo construído com base na autonomia intelectual e na discussão colegiada.

Nas práticas acadêmicas pautadas no autoritarismo, as escolhas e as decisões são impostas pelos docentes aos discentes, que assumem uma postura passiva no processo de aprendência e reagem manifestando conflitos e resistências de forma tácita ou explícita (PÉREZ-GÓMEZ, 2001). Entretanto, a docente 1 indica outro aspecto metodológico a ser considerado: a dificuldade que algumas áreas de conhecimento têm de propor metodologias ativas, participativas e colaborativas nas salas de aula virtuais.

Considerando a situação apresentada, propomos a seguinte reflexão: Será que as especificidades de cada área de conhecimento reduzem ou eliminam a possibilidade de se trabalhar com metodologias ativas, participativas e colaborativas no AVA Moodle? Essa dificuldade está relacionada ao conjunto de conteúdos e às metodologias específicas da disciplina? Ou está vinculada à concepção teóricometodológica que orienta a prática acadêmica do/a docente?

Conforme afirma Libâneo (2003), a metodologia precisa ser pensada em seu sentido mais amplo, como um caminho pelo qual os discentes serão levados a pensar, analisar e fazer conexões que fomentem aprendizagens significativas que visem à ampliação do conteúdo e à forma de pensar.

Com a ideia de que a qualidade do ensino na universidade e o trabalho docente estão intimamente ligados, Libâneo (2003) explica que qualquer mudança que se queira efetivar na universidade precisa ser pensada a partir da discussão entre os pares no curso, com uma gestão participativa. Cabe aos sujeitos da educação (gestor, docente, discente) empreenderem esforços para transformar a cultura e as práticas acadêmicas.

A docente 6 empreendeu esforços para fazer com que os discentes participassem do planejamento da prática acadêmica. Esse pode ser indício de uma ressignificação cultural, que pode fazer com que os discentes saiam da condição de passividade, dialoguem com os docentes e se tornem sujeitos de seus processos de aprendência. Se a ideia de "ensinar bem" estiver, antes de tudo, relacionada à pergunta sobre "como os discentes aprendem?", é evidente a importância de colocá-los como sujeitos ativos no processo de aprendência, sobretudo, tomando decisões (LIBÂNEO, 2003). 
A utilização dos recursos disponíveis na sala de aula virtual e quaisquer outros esforços empreendidos para proporcionar experiências de aprendizagem diversificadas são bem-vindos. Porém, é preciso saber como esses recursos serão empregados no processo de aprendência, uma vez que sua inserção, por si só, não garante que as aprendizagens sejam significativas. Pensar em práticas acadêmicas que atendam às demandas da era digital requer uma reflexão sobre como proceder para que os discentes consigam transformar as muitas informações fragmentadas em conhecimento, sejam capazes de aplicá-lo nas situações cotidianas e concebam o ato de ensinar como aquele em que os discentes sejam expostos a atividade de aprendizagem (LIBÂNEO, 2003).

O docente 4 menciona a disponibilização de um trabalho construído pela discente tanto para os colegas de turma quanto para outra universidade. Valorizar o conhecimento produzido pelo discente é uma forma de desconstruir a ideia de que o professor é detentor absoluto do conhecimento, de possibilitar uma participação mais ativa e de tornar o discente protagonista do processo de aprendência, ajudando a fazer das salas de aula virtuais ou presenciais poderosos espaços de aprendizagem, de investigação, de compartilhamento, de aplicação e de reflexão, para atender às emergências da era digital (PÉREZ-GÓMEZ, 2010).

Para "descentralizar o conhecimento", também é preciso estabelecer uma relação horizontal e uma comunicação clara entre os aprendentes. Contudo, os contextos socioculturais diversos aos quais pertencem os docentes e os discentes colaboram para que ocorra o que Certeau (2012) chamou de "metaforização da língua". Essa expressão refere-se aos ruídos na comunicação, decorrentes do abismo entre os referenciais e as vivências dos interlocutores. No ambiente virtual de aprendizagem, especialmente, a comunicação entre os aprendentes é predominantemente assíncrona e por meio da linguagem escrita. Esse tipo de comunicação requer cautela e desconfiança por parte dos docentes em relação às palavras empregadas na composição das mensagens e dos recursos didáticos.

Segundo Certeau (2012), em algumas circunstâncias, os docentes empregam a metaforização da língua intencionalmente, para se expressar de modo que não possam ser facilmente compreendidos pelos discentes e se afirmarem como detentores de um saber de ordem superior. Esse tipo de comunicação acaba por instituir uma cultura do silêncio na universidade, porque faz o discente acreditar que a discussão e o diálogo com os docentes são inúteis, inférteis 
ou impossíveis. O silêncio é virtual e presencial nas salas de aula da universidade. $\mathrm{O}$ fato de os discentes não participarem voluntariamente do AVA pode ser a manifestação de uma resistência tácita ao modelo de ensino instituído e imposto pela universidade. Esse também é um elemento importante sobre o qual se deve discutir.

A participação voluntária reclamada pelo discenteé demandada pelas práticas de comunicação típicas da cibercultura, nas quais os sujeitos se envolvem em diálogos relacionados com seus interesses de conhecimento. Pérez-Gómez (2001) afirma que a era digital requer saberes de ordem superior. Esses saberes dizem respeito à capacidade de organizar ideias a favor de um pensamento independente, fundamentado e contextualizado. Assim, a cooperação, a participação não coercitiva, a flexibilização e o intercâmbio seriam elementos essenciais para a aquisição do conhecimento e sua aplicação, por meio de uma relação de troca horizontal entre os pares acadêmicos.

Então, nesse caso específico, como explicar o motivo pelo qual os discentes não participaram, quando livres, da obrigação de interagir no AVA Moodle? Como motivar e promover a participação efetiva e voluntária dos discentes, se eles próprios entendem sua ação como vinculada à quantificação do seu desempenho acadêmico?

Ainda sobre as dificuldades enfrentadas pelos aprendentes docentes e discentes no AVA, evidenciou-se uma inapropriação cultural do sistema informático AVA Moodle. Os aprendentes não conhecem os recursos disponíveis nem os incorporaram em suas práticas acadêmicas cotidianas. Eles não conhecem amplamente o potencial pedagógico do Moodle.

Com base nas questões pontuadas, inferimos que talvez fosse preciso ressignificar a concepção metodológica do trabalho no AVA Moodle. Naturalizar seu uso por compreender que se trata de uma extensão da sala de aula presencial e, portanto, é mais um artefato da cultura acadêmica como tantos outros que é fundamental para que consigamos testar suas potencialidades e criar formas de proporcionar um ambiente interessante e desafiador aos olhos dos discentes.

\section{AVALIAĈ̣̃O}

No tocante à avaliação, predominaram práticas acadêmicas baseadas em critérios quantitativos para avaliar o desempenho acadêmico dos discentes nas salas de aula virtuais. Atividades como envio de arquivo, lição e questionário, que favorecem uma avaliação quantitativa, foram as mais utilizadas. Dificilmente acompanhada de 
feedback, essa forma de avaliar põe a finalidade do ensino somente no cumprimento de um rito institucional de uma avaliação classificatória, sem que sejam desfeitos os possíveis equívocos dos discentes.

Nas salas de aula virtuais do AVA Moodle, as atividades fórum, glossário e wiki podem ser opções para modificar as práticas avaliativas quantitativas, porque favorecem a avaliação qualitativa da aprendizagem, com ênfase na autonomia, no diálogo e na colaboração entre os docentes e os discentes. Nesse tipo de avaliação, o feedback do docente se configura como um elemento central, porque ajuda o discente a refletir sobre os equívocos cometidos e a reorganizar o pensamento.

Garcia (2009) ressalta que as práticas avaliativas são formativas e influenciam o modo como os discentes organizam seu tempo, suas prioridades e seus significados, refletindo sobre como se desenvolvem. A partir disso, pensemos: Em que medida o tipo de avaliação adotada pode intervir na formação dos discentes na universidade?

Como se pôde observar na análise dos dados, o modelo estabelecido pela universidade pesquisada é o da avaliação quantitativa. Assim, por mais que o docente busque outras estratégias para avaliar, no final, ele precisa traduzir o desempenho acadêmico dos discentes em uma nota (número), que, nem sempre, reflete as reais aprendizagens alcançadas. Bassani e Behar (2006) afirmam que a avaliação quantitativa tem limitações, porém pode subsidiar a avaliação qualitativa. Assim, seria interessante encontrar um modo de combinar ambos os tipos de avaliação.

QUADRO 5. Avaliação

\begin{tabular}{|c|c|c|}
\hline Identificação & Categoria & \multicolumn{1}{c|}{ Recorte da fala } \\
\hline DOCENTE 2 & $\begin{array}{c}\text { Avaliação } \\
\text { quantitativa }\end{array}$ & $\begin{array}{l}\text { A gente tem que traduzir o rendimento desse aluno } \\
\text { em nota. }\end{array}$ \\
\hline DOCENTE 5 & $\begin{array}{c}\text { Avaliação } \\
\text { quantitativa }\end{array}$ & $\begin{array}{l}\text { [..] a gente tenta favorecer a participação deles } \\
\text { na plataforma para que eles, pelo menos, tenham } \\
\text { interesse em acompanhar a disciplina. }\end{array}$ \\
\hline DOCENTE 6 & $\begin{array}{c}\text { Avaliação } \\
\text { formativa }\end{array}$ & $\begin{array}{l}\text { Autoavaliação na própria plataforma. [...] É uma } \\
\text { possibilidade que eu vejo. Já experimentei aqui no } \\
\text { estudo. }\end{array}$ \\
\hline
\end{tabular}

Fonte: Dados coletados pela pesquisa em março de 2015.

Em relação ao uso do AVA Moodle, os docentes entrevistados disseram que, em geral, não atribuem uma nota à participação dos 
discentes na sala de aula virtual por se tratar de disciplinas de cursos presenciais. Alguns deles observam e consideram essa participação discente e atribuem uma pontuação às avaliações obrigatórias. Contudo, mesmo imersos em uma cultura acadêmica ainda propensa a classificar, muitos discentes deixam de participar das atividades propostas no AVA Moodle porque sabem que não valerão uma nota.

Para Laguardia, Portela e Vasconcelos (2007), em termos de avaliação, seria ideal que se adotasse um modelo de avaliação que combinasse as funções diagnóstica, formativa e somativa. Com tal combinação, poderia se fazer um levantamento do conhecimento prévio do discente e suas dificuldades, expectativas, estilos de aprendizagem e desenvolvimento das habilidades.

Tendo em vista o que foi apresentado, seria preciso repensar os fundamentos teóricos, os instrumentos e os critérios de avaliação na universidade. Para elevar a qualidade do ensino e da aprendizagem universitários, precisamos pensar em formas de avaliar que considerem a subjetividade das experiências e dos contextos diversos de onde vêm os discentes, o percurso acadêmico realizado e os objetivos estabelecidos. Nesse contexto, a avaliação é um elemento que pode contribuir para a reflexão sobre o processo de aprendência pelos docentes e discentes. Para isso, pode-se propor uma participação não coercitiva e integradora aos discentes nas salas de aula virtuais. Nesse tipo de prática avaliativa, os benefícios de aprendizagem são evidenciados em detrimento do controle sobre a aprendizagem e dos erros cometidos. Essa é apenas uma das estratégias de avaliação que pode motivar o discente a participar das salas de aula virtuais no AVA Moodle e promover uma apropriação cultural dessa tecnologia intelectual digital pela universidade.

A forma como os discentes percebem o momento de aprendizagem e o posicionamento do docente pode influenciar suas atitudes de aprendizagem. De maneira geral, o tipo de avaliação predominante nas salas de aula virtuais analisadas favorece atitudes de aprendizagem superficiais, uma vez que põe sua finalidade nos resultados do processo de ensino e aprendizagem. A reflexão sobre a avaliação, no ensino superior, pode contribuir para que os discentes analisem o que foi aprendido e apliquem o conhecimento produzido em diferentes situações e contextos. Para isso, é preciso ter clareza teórica e metodológica sobre os métodos, os instrumentos e os critérios de avaliação a serem utilizados para que os discentes compreendam as intenções do ensino (GARCIA, 2009). 


\section{CONCLUSÕES}

Nas análises de dados desta pesquisa, constatamos que as práticas acadêmicas identificadas nas salas de aula virtuais no AVA - Moodle apresentavam permanências relativas à função acadêmica instrumental e pragmática do ensino e do trabalho docente individual e isolado, como elementos característicos da cultura acadêmica instituída na universidade. A lacuna na formação docente e a precarização do seu trabalho na universidade também são variáveis que têm colaborado para a subutilização dos recursos disponíveis nas salas de aula virtuais do AVA - Moodle e para a predominância de práticas instrumentais de uso dessa tecnologia intelectual digital no processo de aprendência. Nesta pesquisa, as práticas acadêmicas nas salas de aula virtuais analisadas tenderam a reproduzir o paradigma de ensino vigente nas salas de aula presenciais.

Embora o trabalho colaborativo, elemento característico das práticas da cibercultura, não predomine na cultura acadêmica da UFPB, os dados coletados apresentaram indícios de que é possível haver hibridação entre essas duas culturas distintas, desde que se ressignifiquem as práticas acadêmicas nessa instituição.

As principais limitações identificadas dizem respeito à infraestrutura tecnológica institucional e às relações de poder estabelecidas entre os aprendentes docentes e discentes. As práticas da cibercultura tendem a se constituir por meio de relações mais horizontais e democráticas de poder, segundo as quais a informação e o conhecimento são produzidos e compartilhados de todos para todos na rede virtual. Portanto, a ressignificação do currículo a partir da horizontalização das relações de poder nos parece um ponto de contato profícuo para hibridar a cultura acadêmica com a cibercultura.

Quanto às metodologias de ensino, a relação entre docentes e discentes revelou-se como um elemento fundamental. Os docentes referiram queépreciso pensar na dimensão humano-afetiva do processo de aprendência e refletir sobre as relações em que esse conhecimento é construído, para redefinir a participação dos discentes no processo de aprendência e na construção do conhecimento na universidade, e embora se reconheça que é necessário reconfigurar as metodologias de ensino, ainda que os docentes queiram, não conseguem fazê-lo. A relação de interdependência entre as especificidades da natureza de cada área de conhecimento/da disciplina e as metodologias de ensino, o desconhecimento pedagógico e técnico do Moodle e a falta de participação voluntária dos discentes no AVA foram apontadas 
pelos docentes como limitações para que possam trabalhar com metodologias mais ativas, participativas e colaborativas. Entretanto, eles citaram algumas iniciativas para fazer com que os discentes participem das atividades acadêmicas e desconstruam a ideia de que só o professor é o detentor do conhecimento.

No modelo de avaliação estabelecido pela UFPB, constatouse a predominância de práticas acadêmicas baseadas em critérios quantitativos para avaliar o desempenho acadêmico dos discentes, cuja pouca participação nas salas de aula virtuais no AVA e os resultados pedagógicos insatisfatórios relatados pelos docentes não puderam ser explicados nesta pesquisa devido ao tipo de avaliação adotada e à obrigatoriedade ou não da participação dos discentes. Por causa disso, sugerimos que seja adotado um modelo de avaliação que combine as funções diagnóstica, formativa e somativa, por que supomos que esse tipo de avaliação poderia motivar a participação e promover a apropriação dessa tecnologia intelectual digital pela cultura acadêmica.

Todas essas constatações indicam que a ressignificação da cultura acadêmica na UFPB, por meio da hibridação com elementos da cibercultura tem sido feita de modo muito restrito. Assim, podese inferir que o uso do Moodle não tem favorecido o processo de hibridação entre elementos da cultura acadêmica e os da cibercultura, em razão, principalmente, da episteme que governa o ensino e a aprendizagem na instituição investigada neste estudo.

Para pensar nas transformações da cultura acadêmica, devese atentar para as práticas acadêmicas que surgem das hibridações com a cibercultura. Isso não sugere a ideia de copiar modelos e práticas da cibercultura ou de outras universidades sem que sejam considerados o contexto e a cultura da instituição. Experimentar práticas interculturais implica ampliar o leque de possibilidades para se refletir sobre um modelo próprio, que atenda às demandas existentes e integre as práticas culturais com a universidade, em um processo permanente de construção e disseminação do conhecimento.

\section{REFERÊNCIAS}

ASSMANN, H. Reencantar a educação: rumo à sociedade aprendente. Petrópolis: Vozes, 1998.

BASSANI, P. S.; BEARH, P. A. Análise das interações em ambientes virtuais de aprendizagem: uma possibilidade para avaliação da aprendizagem em EAD. Novas tecnologias na Educação, Porto Alegre, v.4, n. 1, jul. 2006. Disponível em: <http://seer.ufrgs.br/renote/ article/viewFile/14044/7932>. Acesso em: 17 out. 2016. 
BEZERRA, L. T. Silva. Cultura acadêmica e tecnologias intelectuais digitais: ensinar e aprender com blogs educativos no Ensino Superior. 256f. Tese (Doutorado em Educação) Programa de Pós-graduação em Educação, Universidade Federal da Paraíba, João Pessoa, 2011.

BEZERRA, I. da S. Cultura acadêmica e tecnologias intelectuais digitais: análise das práticas acadêmicas no ambiente virtual de aprendizagem. 67f. Trabalho de Conclusão de Curso (Licenciatura de Pedagogia) - Centro de Educação, Universidade Federal da Paraíba, João Pessoa, 2016.

BIZZOCCHI, A. Anatomia da cultura: uma nova visão sobre ciência, arte, esporte e técnica. São Paulo: Palas Athena, 2003.

CANCLINI, N. G. Diferentes, desiguais e desconectados: mapas da interculturalidade. Tradução Luiz Sérgio Henriques. $2^{\mathrm{a}}$ ed. Rio de Janeiro: Editora UFRJ, 2007.

CANCLINI, N. G. Culturas híbridas: estratégias para entrar e sair da Modernidade. Tradução Heloíza Pezza Cintrão, Ana Regina Lessa; tradução da introdução: Gênese Andrade. $4^{a}$ ed. 4.Reimp. São Paulo: EdUSP, 2008.

CERTEAU, M. de. A cultura no plural. Tradução Enid Abreu Dobránszky. São Paulo: $7^{\mathrm{a}}$ ed. Papirus, 2012.

DUARTE, A. R S. Cultura acadêmica e cultura escolar: relações entre matemáticos e professores de matemática, Diálogo Educ., Curitiba, n. 25, v. 8, p. 647-662, set./dez. 2008.

GARCIA, J. Avaliação e aprendizagem na educação superior. Estudos em Avaliação Educacional, v. 20, n. 43, p. 201-213, 2009. Disponível em: <http://www.difdo.diren. prograd.ufu.br/Documentos/Avaliacao_e_Aprendizagem_Ensino_Superior.pdf $>$. Acesso em: 17 out. 2016.

GERHARD, V. A idéia de Humboldt: sobre a atualidade do programa de Wilhelm Von Humboldt. In: RONDEN, V. (org.). Idéias de Universidade. Canoas: Ed. ULBRA Filosofia, cap. 1, p. 13-34, 2002.

GOMES, M. J. Blogs: um recurso e uma estratégia pedagógica. 2005. Disponível em: <http://repositorium.sdum.uminho.pt/bitstream1822/4499/1/Blogs-final.pdf. Acesso em: 22 mar. 2010.

LAGUARDIA, J.; PORTELA, M. C.; VASCONCELLOS, M. M. Avaliação em ambientes virtuais de aprendizagem. Educação e pesquisa, São Paulo, v. 33, n. 3, p. 513-530, set./ dez. 2007. Disponível em: <http://www.scielo.br/pdf/ep/v33n3/a09v33n3.pdf> Acesso em: 22 mar. 2010.

LARAIA, R. de B. Cultura: um conceito antropológico. 24ª ed. Rio de Janeiro: Jorge Zahar Ed., 2009.

LÉVY, P. As tecnologias da inteligência: o futuro do pensamento na Era da Informática. Tradução Carlos Irineu Costa. Rio de Janeiro: Ed. 34, 1993 (Coleção Trans.).

LÉVY, P. Cibercultura. Tradução Carlos Irineu Costa. São Paulo: Ed. 34, 1999. 
LIBÂNEO, J. C. Questões de metodologia do Ensino Superior - A teoria históricocultural da atividade de aprendizagem. Escrito para a XIII Semana do Planejamento Acadêmico Integrado da UCG, Goiânia, 2003.

PÉREZ GÓMEZ, Á. I. A cultura escolar na sociedade neoliberal. Tradução Ernani Rosa. Porto Alegre: Artmed, 2001.

PÉREZ GÓMEZ, Á. I. Nuevas exigencias y escenarios para la profesión docente en la era de la información y de la incertidumbre. Revista Interuniversitaria de Formación del Profesorado [online], vol. 24, n. 2, ago. 2010, pp. 17-36. Disponível em: <http://www. redalyc.org/articulo.oa?id=27419198002> . Acesso em: 14 abr. 2015.

PAIVA, V. M. de O. Ambientes virtuais de aprendizagem: implicações epistemológicas, Educ. Rev., Belo Horizonte, v. 26, n. 3, p. 353-370, dez. 2010. Disponível em: <http:// www.scielo.br/scielo.php?script=sci_arttext\&pid=S0102-46982010000300018\&lng=en\&nr $\mathrm{m}=$ iso > . Acesso em: 21 out. 2013.

ROCHA, P. J.; MONTARDO, S. P. Netnografia: incursões metodológicas na cibercultura, E-compós, p. 13-22, dez. 2005. Disponível em: <http://www.compos.com.br/e-compos>. Acesso em: 09 mai. 2010.

SANDÍN ESTEBAN, M. P. Pesquisa qualitativa em educação: fundamentos e tradições. Tradução Miguel Cabrera. Porto Alegre: AMGH, 2010.

SANTOS, M. L. dos. Extensão universitária e interdisciplinaridade: uma discussão em torno da universidade contemporânea, s/d. Disponível em: <http://www.pucpr.br/eventos/ educere/educere2006/anaisEvento/docs/CI-254-TC.pdf>. Acesso em: 14 ago. 2015

SILVERMAN, D. Interpretação dos dados qualitativos: métodos para análises de entrevistas, textos e interações. $3^{\mathrm{a}}$ ed. Porto Alegre: Artmed, 2009.

SOARES, E. M. do S.; VALENTINI, C. B.; RECH, Jane. Convivência e aprendizagem em ambientes virtuais: uma reflexão a partir da biologia do conhecer, Educ. Rev., Belo Horizonte, v. 27, n. 03, p. 39-59, dic. 2011. Disponível em: < http://educa.fcc.org.br/scielo. php?script $=$ sci_arttext\&pid=S0102-46982011000300003\&lng $=$ es\&nrm=iso $>$. Acesso em: 21 out. 2013.

\section{NOTAS}

${ }^{1}$ No livro, "Cultura: um conceito antropológico", Laraia (2009) apresenta o desenvolvimento do conceito de cultura com as diferentes concepções e suas formulações para o termo.

${ }^{2}$ Os instrumentos de coleta dos dados estão disponíveis para ser enviados pela pesquisadora através do e-mail: irinaldabezerra@gmail.com.

${ }^{3}$ Para mais informações sobre o AVA, consulte: http://docs.moodle.org/pt_br/ Endereço eletrônico do AVA - Moodle dos cursos presenciais da UFPB: http://presencial.virtual.ufpb.br 
Submetido: 19/10/2017

Aprovado: 12/07/2018

Contato:

Lebiam Tamar Gomes Silva

Rua Univ. Maria das Graças Ribeiro Alencar, n. 251, apto. 202, Ed. Maria Eduarda, Bessa João Pessoa $|\mathrm{PB}|$ Brasil

CEP 58.035-400 